Quim. Nova, Vol. 36, No. 9, 1468-1476, 2013

\title{
DA ESCASSEZ AO ESTRESSE DO PLANETA: UM SÉCULO DE MUDANÇAS NO CICLO DO NITROGÊNIO
}

\author{
Gabriel Garcia e Arnaldo Alves Cardoso* \\ Departamento de Química Analítica, Instituto de Química, Universidade Estadual Paulista, Rua Professor Francisco Degni, 55, \\ CP 355, 14800-900 Araraquara - SP, Brasil \\ Oalas Aparecido Morais dos Santos \\ Instituto Federal de Educação, Ciência e Tecnologia de Mato Grosso, Campus São Vicente, BR 364, km 329, $78106-000$ Santo \\ Antônio do Leverger - MT, Brasil
}

Recebido em 24/1/13; aceito em 12/6/13; publicado na web em 25/7/13

\begin{abstract}
FROM SHORTAGE TO STRESS ON EARTH: A CENTURY OF CHANGES IN THE NITROGEN CYCLE. Heavy metals and pesticides are usually associated with the main problems humankind has created in the natural environment. However, compounds with characteristics of essential macronutrients are causing serious environmental changes that could intensify, compromising the diversity of life on the planet. This is the case of nitrogen compounds, produced by industrial processes for use in intensive agriculture in addition to those unwittingly produced from human activities, available in excess in the environment. These compounds warrant greater attention from researchers in various fields of knowledge and public agencies for environmental control, toward minimizing their availability in the environment, thereby returning conditions closer to the natural environmental balance of the planet.
\end{abstract}

Keywords: nitrogen cycle; reactive nitrogen; intensive agricultural.

\section{INTRODUÇÃO}

"A fixação do nitrogênio é de importância vital para o progresso da humanidade civilizada, e, ao menos que possamos classificá-la entre as realidades do futuro, a grande raça Caucásica deixará de ser a primeira do mundo, alijada da existência pelas raças para as quais o pão de trigo não é o esteio da vida. A fixação do nitrogênio atmosférico é, portanto uma grande descoberta aguardando os químicos (...)". ${ }^{1}$ Estas ideias permearam o discurso de posse de William Crookes na presidência da Associação Britânica para o Avanço da Ciência, 1898. Esta fala precisa ser contextualizada no tempo em todos os seus aspectos. Aqui discutiremos sobre o contexto da necessidade de fixação do nitrogênio. A falta de nitrogênio reativo para produção de fertilizantes aparecia então como o primeiro problema global que ameaçava o desenvolvimento da humanidade. O mais incrível é que em 2009, pouco mais de cem anos após o discurso de Crookes, um grupo de pesquisadores liderados por Johan Rockstrom divulga um artigo $^{2}$ apresentando nove potenciais processos ambientais básicos que podem comprometer a saúde do planeta e a vida como atualmente está estabelecida. Agora o excesso de nitrogênio reativo disperso no ambiente é colocado junto com dois outros processos ambientais que merecem atenção especial pelo alto potencial em interferir na capacidade do planeta de sustentar a vida humana nos próximos anos. A aparente contradição é uma história que mostra como o lado do "bem" e do "mal" nem sempre podem ser facilmente separados. Especialmente quando vários fatores estão entrelaçados como economia, segurança alimentar e bem estar social fazem contraponto com o ambiente em equilíbrio. Buscaremos aqui discutir como a solução de um problema como produção de nitrogênio reativo, fundamental para manter a continuidade da vida no planeta, rapidamente alterou o ambiente e pode ameaçar a vida estabelecida como um todo no planeta.

O nitrogênio é um elemento essencial para formação dos organismos vivos, ele é componente do RNA, DNA e proteínas, desta forma a disponibilidade de nitrogênio em forma assimilável é fundamental

*e-mail: acardoso@iq.unesp.br para a continuidade da vida no planeta. Para o homem a única forma de obter nitrogênio á através de alimentos. O nitrogênio disponível biologicamente é aquele que está ligado a carbono, oxigênio ou hidrogênio e é conhecido como nitrogênio reativo. $\mathrm{O}$ nitrogênio é um dos elementos mais abundante na Terra, ${ }^{3}$ com o cerca de $4 \times 10^{21}$ g distribuídos na atmosfera, solo e água, mas apenas $0,02 \%$ estão disponíveis para os seres vivos. ${ }^{4} \mathrm{O}$ nitrogênio atmosférico é composto de dois átomos ligados por seis elétrons que formam a tripla ligação covalente $(\mathrm{N} \equiv \mathrm{N})$. A força de ligação é notavelmente elevada e a energia de dissociação é de $225,2 \mathrm{kcal} / \mathrm{mol}^{5}$, fato que garante alta estabilidade para a molécula. $\mathrm{O}$ termo fixação utilizado neste texto tem origem na alquimia e seu significado em uma tradução livre significa "a conversão de um espírito volátil e móvel para uma forma corpórea". Entende-se que a fixação do nitrogênio é um processo de transformar o gás $\mathrm{N}_{2}$ em uma forma manipulável que pode ser, por exemplo, a amônia na forma líquida ou o sal $\mathrm{NH}_{4} \mathrm{NO}_{3}{ }^{6}$

Os raios formados em tempestades podem quebrar esta ligação e formar óxidos de nitrogênio, contribuindo para a inserção de 2-20 Mt de nitrogênio reativo por ano no ambiente. ${ }^{7}$ A maior parte do nitrogênio fixado naturalmente provém de bactérias adaptadas como as do gênero Rhizobium que vivem em nódulos de raízes de plantas leguminosas. ${ }^{8}$ A fixação natural em ambientes terrestres é da ordem de 90-130 Tg N ano ${ }^{-1}$ e no ecossistema marinho é da ordem de 20-200 $\mathrm{Tg} \mathrm{N}^{-1} \mathrm{ano}^{-1}\left(\mathrm{Tg}=10^{12} \mathrm{~g}\right) .^{9}$

Como o nitrogênio é um macronutriente essencial, este deve estar sempre disponível no solo para o crescimento dos vegetais. Em ambientes naturais a ciclagem do nitrogênio entre as várias espécies reativas garante a disponibilidade necessária para manter o equilíbrio do ecossistema. O ciclo do nitrogênio possui varias espécies gasosas e íons altamente solúveis em água o que facilita a dispersão dos compostos de nitrogênio no ambiente.

Ao final da safra de uma cultura agrícola o produto da colheita contendo nitrogênio incorporado a ele é levado para o centro de consumo. Com isto é necessário incorporar ao solo anualmente uma reposição do nitrogênio, de outra maneira o solo ficaria exaurido diminuindo a produtividade na safra seguinte. Estudos feitos entre 
2003-2005 comparando regiões similares para o cultivo agrícola no Quênia e China ${ }^{10}$ mostram que cerca de $50 \mathrm{~kg}^{\mathrm{de} \mathrm{N}} \mathrm{Na}^{-1} \mathrm{ano}^{-1}$ são exauridos do solo do oeste do Quênia. A baixa produtividade agrícola e a fome são consequências da impossibilidade de repor nutrientes no solo nesta parte da África, resultado do custo relativo elevado de fertilizantes. Em região do norte da China, com índice de pluviosidade similar ao oeste do Quênia e onde o fertilizante é subsidiado e adicionado em excesso, há uma sobra de nitrogênio de cerca de $227 \mathrm{~kg}$ de $\mathrm{N} \mathrm{ha}^{-1}$ ano $^{-1}$ e a região exporta alimentos. Duas regiões com condições extremas onde a fome ou a fartura são resultado do balanço do nitrogênio e em ambas as consequências ambientais caminham para o desequilíbrio do que poderia se chamar sustentabilidade.

Durante o século XIX a população mundial aumentou em aproximadamente $60 \%$, com destaque para a Europa, que impulsionada pela revolução industrial, passou de 200 milhões para 400 milhões de habitantes nesse período. ${ }^{11} \mathrm{~A}$ demanda por alimentos crescia, mas a produtividade de cada hectare estava limitada a cerca de $200 \mathrm{~kg}$ de nitrogênio reposto no solo por reciclagem de dejetos humanos e de animais. O solo recomposto desta forma poderia produzir alimentos para consumo de cerca de 15 pessoas ha ${ }^{-1} \mathrm{ano}^{-1}$, fato que apontava para produção de alimentos sem perspectiva de crescimento. ${ }^{12}$

A ciência buscava entender o que poderia afetar o crescimento de vegetais. Boussingault trabalhando na França entre 1830-60 mostrou a importância do nitrogênio para aumentar a produtividade das culturas o que foi um passo importante para o estabelecimento das bases da agroquímica. ${ }^{13} \mathrm{O}$ químico J. von Liebig baseado em seus experimentos e nos resultados de Boussingault estabeleceu os princípios teóricos de nutrição de plantas no artigo Chemistry in Its Application to Agriculture and Physiology. ${ }^{14}$ Isto possibilitou reconhecer a necessidade de suprir o solo com nitrogênio para compensar o que é retirado no produto do cultivo. A prática de adicionar fertilizantes nitrogenados passou a ser incorporada na produção agrícola. A principal característica é que este nitrogênio deveria ser abundante o suficiente para favorecer nutriente de baixo custo. Até o século XIX, a necessidade de nitrogênio para a cultura agrícola provinha de excrementos de animais e de salitre obtido de minas no deserto do Chile. O guano (fezes de pássaros) encontrado em ilhas ao largo da costa oeste da América do Sul foi uma importante fonte de fertilizante, mas que ao final do século XIX estava quase esgotada. ${ }^{12}$

Os depósitos de salitre constituíam cerca de dois terços das necessidades de nitrogênio, mas estavam distantes do local de consumo e ainda estudos da época eram divergentes sobre as reservas de nitrato existentes. Alguns indicavam o esgotamento em 25 ou 30 anos, outros que ainda poderiam durar 3 ou 4 centenas de anos. Uma das causas desta grande divergência é devida à forma de exploração do governo do Chile sobre as minas de salitre, não estimulando explorações individuais em novas áreas, o que levava a conclusões pessimistas sobre esgotamento das reservas existentes. ${ }^{15}$

Além da agricultura, a demanda por compostos de nitrogênio também era pressionada pelas fábricas de corantes e gás amônia para indústria de refrigeração, ambas em expansão, mas o mais forte concorrente pelo uso dos compostos de nitrogênio era a produção de explosivos: pólvora, TNT e nitroglicerina, produtos essenciais produzidos pelas indústrias bélicas. ${ }^{14,16}$ Há muito se sabe que o poderio das forças bélicas dependia de explosivos e exércitos bem alimentados, ambos, produtos dependentes diretamente e indiretamente de compostos de nitrogênio. ${ }^{17}$

Este era o panorama evidenciado por William Crookes que levou o cientista a conclamar os Químicos para uma busca alternativa para a fixação do nitrogênio, isto é, buscar um método químico viável e econômico para produzir um composto de nitrogênio reativo.

\section{A SÍNTESE DA AMÔNIA E A PRODUÇÃO DE FERTILIZANTES NITROGENADOS}

A síntese e produção comercial da amônia são possivelmente os principais marcos da química no século XX. A produção de fertilizantes nitrogenados não apenas possibilitou produção de alimentos para saciar a fome da população, mas junto com a revolução verde possibilitou que a população do planeta ultrapassasse em 2012 a marca de 7 bilhões de habitantes..$^{15}$ Considerando-se que habitavam o planeta 1 bilhão e 600 milhões de pessoas em $1900,{ }^{10}$ o número de habitantes acrescido ao planeta desde então só foi possível com a maior produção de alimentos e estes podem ser convenientemente chamados de os "filhos do nitrogênio". ${ }^{14}$ Sem a fixação industrial de nitrogênio originada pelo processo Haber-Bosch seria necessário um aumento de $167 \%$ no espaço destinado ao cultivo agrícola para atender a demanda populacional atual e uma expansão de $225 \%$ nesse espaço para atender uma população estimada em 9,2 bilhões para $2050{ }^{18}$

Nada funciona para o homem com fome: saúde, educação, arte, ciência e tecnologia, portanto é difícil medir o alcance proporcionado pela fixação intencional do nitrogênio nos anos que se seguiram ao processo Haber-Bosch. Mesmo as mudanças na geopolítica do inicio do século XXI, com a entrada em cena de países emergentes (BRICS), só foi possível porque estes possuem forte sustentação econômica baseado no agronegócio fruto direto da disponibilidade de nitrogênio. Talvez nenhuma descoberta tenha mudado tanto a história da humanidade. Criteriosa descrição histórica sobre a busca e síntese da amônia foi apresentada por A. Chagas. ${ }^{19} \mathrm{O}$ processo mais bem sucedido foi desenvolvido por Fritz Haber e seu colaborador Robert Le Rossignol em 1909. Mas, as altas temperatura e pressão danificavam a câmara da síntese produzida em aço inviabilizando o seu uso contínuo. Posteriormente, Carl Bosch contribuiu para superar as grandes dificuldades do processo de produção em larga escala. O processo de fixação do nitrogênio ficou conhecido como Haber-Bosch. No início da I Guerra Mundial, Haber ofereceu sua criatividade e habilidade cientifica ao governo alemão. Neste papel ele desenvolveu o uso do gás cloro como arma; posteriormente planejou e comandou em campo o primeiro ataque com armas químicas da história (em Ypres, Bélgica, 22/4/1915), fato que supostamente contrariou e motivou o suicídio de sua esposa, ocorrido uma semana depois. ${ }^{11,20}$ Haber, em 1918, juntamente com Bosch (1931), recebem o Prêmio Nobel de Química, pelas contribuições relacionadas à síntese da amônia.

Com base no processo Haber-Bosch a Alemanha iniciou a fabricação em larga escala de amônia na cidade de Oppau, em 1913. Sua capacidade anual de 8700 toneladas foi aumentada para 60.000 toneladas até o final de 1915. Uma segunda planta foi concluída em Leona, a oeste de Leipzig, em 1918. Juntas, elas forneceram compostos nitrogenados para a Alemanha durante a primeira guerra. Sem elas, o bloqueio imposto pela entrada de salitre do Chile provavelmente levaria à falta de munição, que seria insuficiente para manter seu esforço de guerra. ${ }^{11}$

A produção de nitrogênio reativo não parou de crescer, resultado não só da demanda espontânea como de melhorias no processo que baratearam o produto final. A produção de fertilizantes dobrou a cada 8 anos entre 1950-1973. Foram mais 17 anos para dobrar a produção novamente. A crise da União Soviética motivou a retirada de subsídios dos fertilizantes, que resultou em diminuição da produção entre 1990-1995. ${ }^{19}$ Voltou a crescer nos anos seguintes e atualmente a produção é superior a $136 \mathrm{Mt}$ por ano. ${ }^{21}$

Importante papel neste processo de crescente consumo de fertilizante nitrogenado foi o desenvolvimento de novas práticas agrícolas para produção em larga escala conhecido como revolução verde. Norman Ernest Borlaug, agrônomo americano e ganhador do premio Nobel da Paz em 1970, foi o nome que mais contribuiu para 
Tabela 1. Perdas de nitrogênio para o ambiente na produção de grãos e carne (adaptada) ${ }^{23,25}$

\begin{tabular}{ccccccc}
\hline \multirow{2}{*}{$\begin{array}{c}\text { Produção } \\
\text { agropecuária }\end{array}$} & $\begin{array}{c}\text { Fertilizante } \\
\text { produzido }\end{array}$ & $\begin{array}{c}\text { Fertilizante } \\
\text { aplicado }\end{array}$ & $\begin{array}{c}\text { Nitrogênio na } \\
\text { cultura agrícola }\end{array}$ & $\begin{array}{c}\text { Nitrogênio } \\
\text { colhido }\end{array}$ & $\begin{array}{c}\text { Nitrogênio no } \\
\text { alimento }\end{array}$ & $\begin{array}{c}\text { Nitrogênio } \\
\text { consumido }\end{array}$ \\
\hline Grãos & 100 & 94 & 47 & 31 & 26 & 14 \\
Carne & 100 & 94 & 47 & 31 & 7 & 4 \\
\hline
\end{tabular}

o aumento da produção global de alimentos. Suas pesquisas com trigo foram um marco na revolução verde. O trigo de haste longa gastava parte de sua energia na formação da planta e quanto maior seu bago mais ele se inclinava em direção ao solo aumentando a chance de perda. Borlaug desenvolveu variedades de trigo anão de alto rendimento, resistente a doenças. Como resultado de suas pesquisas, o México, Índia e Paquistão tornaram-se autossuficientes e posteriormente exportadores de grãos. Porém, estas novas variedades se mostraram altamente dependentes de fertilizantes nitrogenados. Segundo Borlaug, "as variedades anãs de alto rendimento são os catalisadores que deflagraram a revolução verde, o combustível foi fertilizante nitrogenado". ${ }^{14}$

O processo de fixação da amônia usa o gás natural como fonte de hidrogênio e segundo relatório apresentado pela International Fertilizer Industry Association, a produção de amônia é responsável pelo consumo de $5 \%$ do gás natural produzido no mundo, que corresponde a cerca de $2 \%$ do potencial de energia produzido. ${ }^{22} \mathrm{~A}$ produção de fertilizantes está diretamente conectada com a produção e custo de energia fóssil. O custo do gás natural representa cerca de $90 \%$ do custo final do fertilizante nitrogenado.

\section{O NITROGÊNIO E SUA DISPERSÃO NO AMBIENTE}

As espécies utilizadas nos fertilizantes nitrogenados, amônio, nitrato e uréia, são muito solúveis em água e isto facilita sua dispersão no ambiente. Aplicadas ao solo no momento do plantio, que usualmente corresponde à estação chuvosa, estes compostos são em parte lixiviados pelas chuvas ou/e por processos de irrigação. Estudos mostram que o aproveitamento efetivo pelas plantas em formação é menor que $40 \%$ do fertilizante inicialmente aplicado. ${ }^{23}$ Como o produto final é apenas parte da planta vegetal, como no caso do milho, o nitrogênio incorporado ao alimento é apenas uma pequena porcentagem do inicialmente adicionado na cultura. ${ }^{24} \mathrm{~A}$ Tabela 1 apresenta estimativa sobre a eficiência do uso final do nitrogênio nas várias etapas do processo de produção de alimento. No caso da produção de grãos para utilização em ração animal, a eficiência é significativamente menor. Sob este aspecto a produção agrícola de açúcar e álcool possui eficiência nula ao final do processo porque ambos os produtos não incorporam nitrogênio na sua molécula. $\mathrm{O}$ fertilizante aplicado é utilizado apenas como um promotor do crescimento da cana de açúcar. O nitrogênio não utilizado acaba ficando no ambiente próximo à produção agrícola (Figura 1).

$\mathrm{O}$ transporte mundial de produtos contendo nitrogênio é muito significativo e já foi contabilizado. As rotas do nitrogênio transportado podem ser contabilizadas pelo comércio entre nações produtoras e consumidoras de nitrogênio contido nos diferentes produtos envolvidos na produção de alimentos. É possível quantificar a troca entre nações produtoras e consumidoras de nitrogênio na forma de fertilizantes nitrogenados, transporte de grãos e finalmente comércio de carnes e derivados entre nações produtoras e consumidoras. ${ }^{26} \mathrm{Os}$ números deste comércio possibilitam uma previsão sobre quais países podem estar mais impactados pelo nitrogênio remanescente no ambiente. Os consumidores de carnes e grãos recebem o nitrogênio já incorporado no alimento final enquanto que os paises produtores

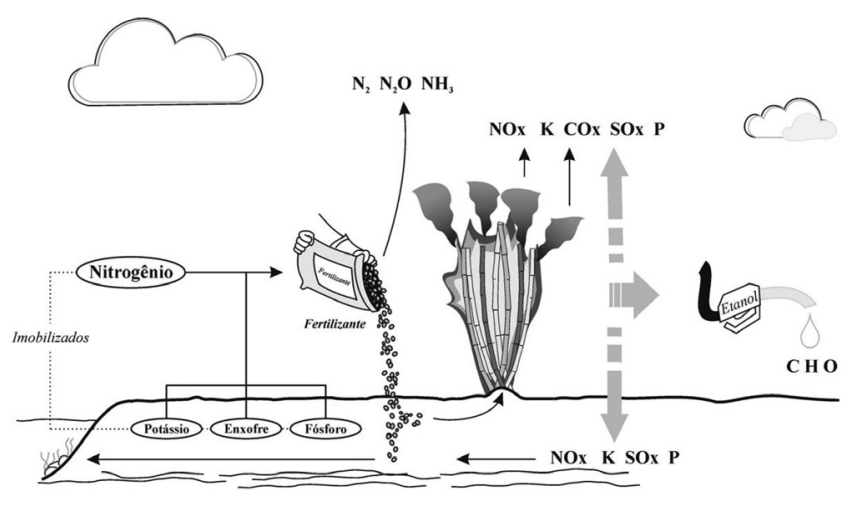

Figura 1. Produção de cana de açúcar e utilização do álcool combustível: um sistema aberto para utilização e dispersão de $N, S, P$ e K

agrícolas padecem com os restos do nitrogênio não utilizado que permaneceram no ambiente. Infelizmente o custo deste nitrogênio que fica remanescente no ambiente não é contabilizado como prejuízo pelos países produtores de grãos. Este passivo ambiental até o momento tem sido um ônus pago por toda sociedade que vive do entorno do agronegócio.

A lei da conservação de massa garante que mesmo o nitrogênio incorporado aos alimentos na forma de proteína, base da alimentação do homem, tem como destino final o ambiente. Os nutrientes não aproveitados pelo homem são eliminados pela sua urina e fezes. A composição do material solúvel e não solúvel de um esgoto residencial é rica em compostos nitrogenados (Tabela 2). ${ }^{27} \mathrm{O}$ destino final do esgoto residencial é invariavelmente um corpo de água natural. Quando este esgoto passa previamente por uma estação de tratamento esgoto (ETE), que no Brasil não ultrapassa cerca de $30 \%$ do total do esgoto residencial produzido, ${ }^{28}$ o processo de depuração biológico induzido transforma os compostos de nitrogênio em amônio ou nitrato. As ETE com processo de tratamento terciário de esgoto que poderia converter o amônio ou nitrato em $\mathrm{N}_{2}$ o que impediria a dispersão destes compostos no ambiente, são inexistentes no Brasil. Como resultado estes íons, provenientes desse tratamento incompleto, são lançados diretamente nos corpos de água superficiais. Na maior parte do esgoto produzido, que corresponde à parte não tratada pelas ETE, os compostos de nitrogênio são transformados em amônio e nitrato por processos naturais biológicos. Portanto, quase todo o nitrogênio presente nos alimentos volta ao ambiente na forma de produtos resultantes da degradação biológica induzida na ETE ou por processos biogeoquímicos nos corpos de água.

\section{FIXAÇÃO NÃO INTENCIONAL DO NITROGÊNIO}

Além da fixação intencional do nitrogênio, atividades humanas que dependem de processos de combustão fazem a fixação de grandes quantidades de nitrogênio de forma não intencional. Todo processo de combustão é resultado de uma reação entre um combustível e o gás oxigênio, componente secundário do ar atmosférico (composição é de $75 \%$ de nitrogênio e $25 \%$ de oxigênio), que produz energia térmica. Esta energia favorece a ocorrência de reações secundárias 
Tabela 2. Processos ambientais que podem colocar em risco a Terra caso sejam ultrapassados seus limites de segurança (adaptada de J. Rockström e colaboradores) ${ }^{2}$

\begin{tabular}{|c|c|c|c|c|}
\hline Processo & Parâmetro utilizado & Limite proposto & Condições atuais & Condições pré-industriais \\
\hline \multirow[b]{2}{*}{ Mudanças climáticas } & $\mathrm{CO}_{2}$ na atmosfera em (ppmv) & 350 & 387 & 280 \\
\hline & $\begin{array}{l}\text { Troca no balanço radiativo da atmosfera } \\
\left(\mathrm{W} \mathrm{m}^{-2}\right)\end{array}$ & 1,0 & 1,5 & 0 \\
\hline Taxa de perda biodiversidade & $\begin{array}{c}\text { Taxa de extinção } \\
\left(\mathrm{n}^{0} \text { espécie/1 milhão espécies }\right) \text { ano }^{-1} \\
\end{array}$ & 10 & $>100$ & $01 .-1$ \\
\hline $\begin{array}{l}\text { Ciclo do nitrogênio - fronteira } \\
\text { com o ciclo do fósforo }\end{array}$ & $\begin{array}{c}\text { Fixação industrial de nitrogênio } \\
\left(\text { milhões ton. } \text { ano }^{-1}\right)\end{array}$ & 35 & 136 & 0 \\
\hline $\begin{array}{c}\text { Espécies de fósforos } \\
\text { compartilhadas com espécies } \\
\text { de N no ambiente } \\
\end{array}$ & $\begin{array}{l}\text { Quantidade de fósforo fluindo para os oceanos } \\
\text { (milhões ton. } \text { ano }^{-1} \text { ) }\end{array}$ & 11 & $8.5-9,5$ & -1 \\
\hline Uso da terra & $\begin{array}{l}\text { Porcentagem do território global } \\
\text { utilizado para agricultura }\end{array}$ & 15 & 11,7 & Pequena \\
\hline $\begin{array}{l}\text { Depleção do ozônio } \\
\text { estratosférico }\end{array}$ & Concentração de ozônio (Dobson) & 276 & 283 & 290 \\
\hline Acidificação oceânica & $\begin{array}{l}\text { Média global do estado de saturação de } \\
\text { aragonita na superfície dos oceanos }\end{array}$ & 2,75 & 2,90 & 3,44 \\
\hline Água para consumo & Consumo de água $\mathrm{km}^{3} \mathrm{ano}^{-1}$ & 4000 & 2600 & 415 \\
\hline Poluição química & $\begin{array}{l}\text { Quantidade emitida de compostos de impacto } \\
\text { relevante no ambiente: compostos orgânicos } \\
\text { persistentes, plásticos, metais pesados, } \\
\text { disruptores endócrinos, etc. }\end{array}$ & A ser determinado & & \\
\hline Emissão de aerossóis & Concentração na atmosfera & A ser determinado & & \\
\hline
\end{tabular}

entre os dois principais componentes do ar com a produção de $\mathrm{NO}(\mathrm{g})$. Transporte utilizando veículos com motores à combustão, usinas termoelétricas e indústrias que utilizam combustíveis em larga escala em seu processo são fontes de emissão do gás NO para atmosfera. Outra fonte significativa de NO é a queima de biomassa. A atmosfera com propriedades oxidantes transforma inicialmente o gás $\mathrm{NO}$ em gás $\mathrm{NO}_{2}$ :

$$
\mathrm{NO}+\mathrm{O}_{3} \rightarrow \mathrm{NO}_{2}+\mathrm{O}_{2}
$$

Posteriormente diferentes reações de oxidação podem ocorrer na troposfera formando como produto principal o ácido nítrico. ${ }^{23}$

$$
\begin{gathered}
\mathrm{NO}_{2}+\mathrm{OH}^{\bullet}+\mathrm{hv} \rightarrow \mathrm{HNO}_{3} \\
\mathrm{NO}_{2}+\mathrm{O}_{3} \rightarrow \mathrm{NO}_{3}^{\bullet}+\mathrm{O}_{2} \\
\mathrm{NO}_{3}^{\cdot}+\mathrm{NO}_{2} \rightleftharpoons \mathrm{N}_{2} \mathrm{O}_{5} \\
\mathrm{~N}_{2} \mathrm{O}_{5}+\mathrm{H}_{2} \mathrm{O} \rightarrow 2 \mathrm{HNO}_{3}
\end{gathered}
$$

A reação (2) ocorre em presença de luz solar e as reações (3) a (5) no período noturno. Posteriormente parte do ácido nítrico pode ser neutralizada pela amônia atmosférica gerando um sólido iônico:

$$
\mathrm{HNO}_{3(\mathrm{~g})}+\mathrm{NH}_{3(\mathrm{~g})} \rightarrow \mathrm{NH}_{4} \mathrm{NO}_{3(\mathrm{~s})}
$$

Processos de deposição seca e úmida podem ocorrer com qualquer dos compostos de nitrogênio envolvidos nas reações acima. ${ }^{29,30} \mathrm{O}$ excesso de nitrogênio presente na atmosfera faz com que a deposição destas espécies nos dias atuais supere em mais uma dezena de vezes a deposição natural de nitrogênio em ambientes remotos. ${ }^{28,31}$

Em 1970, atividades humanas relacionadas à produção de fertilizantes, combustão de combustíveis e cultivo de leguminosas mobilizaram cerca de $70 \mathrm{Tg} \mathrm{N}$ ano ${ }^{-1}$. Em meados dos anos 90, a mobilização chegou em $140 \mathrm{Tg} \mathrm{N}$ ano ${ }^{-1}$. A fixação natural em ambientes terrestres é da ordem de 90-130 Tg N ano ${ }^{-1}$. Com isto, atividades antrópicas relacionadas à produção de alimentos e uso de combustíveis já superaram significativamente a mobilização de compostos reativos de nitrogênio no ciclo natural deste elemento. ${ }^{8}$

\section{CONSEQUÊNCIAS DO EXCESSO DE NITROGÊNIO NO AMBIENTE}

$\mathrm{O}$ excesso de nitrogênio no ambiente é um inconveniente em vários aspectos (Figura 1). Vários relatos na literatura apresentam os problemas da disponibilidade do elemento e seus efeitos no ambiente. $\mathrm{O}$ artigo antes citado, encabeçado por Johan Rockstrom ${ }^{2}$ com a colaboração de 28 pesquisadores, buscou estabelecer valores para nove processos ambientais básicos que, tendo os seus limites ultrapassados, podem ameaçar a sustentabilidade da Terra. A complexidade destes processos é enorme, tanto que só foi possível estabelecer a faixa numérica de segurança onde a humanidade pode operar com segurança para sete deles (Tabela 2). Para a emissão de aerossóis e poluição química ainda não existem dados suficientes para estabelecer quaisquer limites numéricos. O estudo sugere que três processos já tiveram seus limites de segurança ultrapassados, e são eles: mudanças climáticas, perda de biodiversidade e excesso de compostos reativos de nitrogênio no ambiente. Para evidenciar a gravidade do problema do excesso de nitrogênio reativo pretendemos mostrar como o nitrogênio possui um papel especial em cada um destes processos contribuindo para estressar o ambiente (Figura 2).

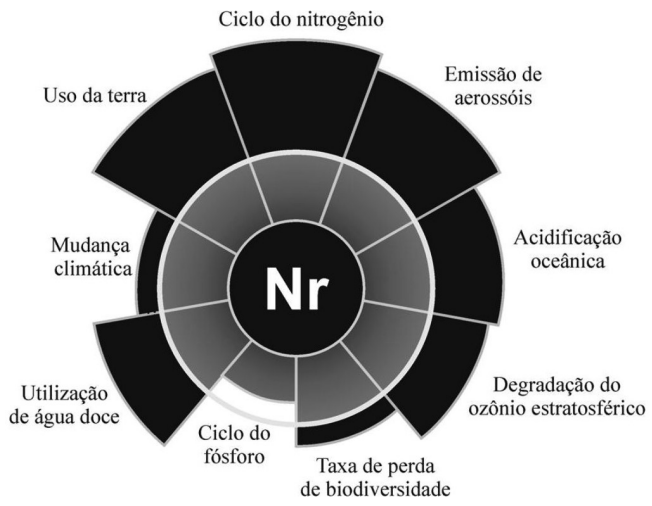

Figura 2. O nitrogênio reativo (Nr) no centro dos processos ambientais que podem colocar a Terra em risco (adaptada de J. Rockström e colaboradores) ${ }^{2}$ 


\section{CICLO DO NITROGÊNIO}

As atividades antrópicas que ocorreram principalmente nos últimos cem anos alteraram o fluxo de nitrogênio reativo entre os diversos reservatórios envolvidos no ciclo biogeoquímico deste elemento. Nas regiões rurais a demanda por alta produtividade nas lavouras levou ao uso intensivo de fertilizantes. Como a eficiência do aproveitamento do fertilizante nitrogenado é mínimo, isto resultou em grande dispersão de compostos de nitrogênio no ambiente. O problema do acúmulo só tende a se agravar porque as culturas anuais requerem fertilizantes no mínimo uma vez por ano e o agronegócio global está em plena expansão. Nas áreas urbanas ou industriais, a queima de combustíveis predomina como fonte de emissão de compostos de nitrogênio reativos para atmosfera e a expectativa é do uso crescente de combustíveis pela inclusão da população dos países que tiveram sucesso com o agronegócio. Já o esgoto residencial tratado ou não é fonte de compostos de nitrogênio para rios e águas costeiras. Não se vislumbra em médio prazo a implantação de ETE com tratamento terciário de esgoto. A crescente utilização de ração na alimentação de animais em substituição de pastagem agrava o problema, não só pelo consumo maior de fertilizante para produzir ração como também pela grande produção de dejetos, que pouco podem ser aproveitados por serem produzidos longe da lavoura. Outra pressão no ciclo do nitrogênio que precisa ser melhor avaliada é a produção de biocombustível. Qual o ganho real ambiental do uso de álcool combustível? O modelo de produção de biocombustível forma um ciclo fechado para os elementos $\mathrm{C}\left(\mathrm{CO}_{2}\right), \mathrm{H}$ e O $\left(\mathrm{H}_{2} \mathrm{O}\right)$, no entanto é aberto em direção ao acumulo ambiental para os macronutrientes: N, P, K (Figura 1). Dados do INPE mostram que 4,89 milhões de hectares de cana foram cultivados somente no Estado de São Paulo em 2010. A adição de $90 \mathrm{~kg}$ de fertilizante por hectare corresponde à aplicação de cerca de 440 mil toneladas de fertilizante nitrogenado. Dados coletados em região produtora de cana de açúcar mostram que cerca de 46 mil ton de nitrogênio/ano foram produzidos na colheita manual. ${ }^{32}$ Os dados mostram que a produção de biocombustível mobiliza muito nitrogênio reativo para o ambiente.

Aspecto importante que tem motivado o uso de biocombustíveis em substituição aos combustíveis fósseis é a intenção de não aumentar o estoque de carbono na atmosfera pela queima destes. Porém estudos têm sugerido que algumas práticas agrícolas da produção de cana de açúcar podem contribuir para maior emissão do gás estufa $\mathrm{N}_{2} \mathrm{O}$, além de outros problemas ambientais provocados pelo excesso de nitrogênio reativo no ambiente. ${ }^{33}$ Certamente ainda é necessário avançar no conhecimento sobre custos ambientais envolvidos no processo de produção e uso de biocombustíveis.

A química do nitrogênio no ambiente provoca efeito em cascata. $\mathrm{O}$ nitrogênio emitido como uma molécula de gás NO na atmosfera de uma metrópole é oxidado a $\mathrm{NO}_{2}$ e este atua como fotocatalisador na formação de ozônio troposférico, principal poluente gasoso que afeta a saúde da população. É responsável pela formação do smog fotoquímico que assola as grandes metrópoles levando a episódios de grande poluição. Posteriormente o gás $\mathrm{NO}_{2}$ pode reagir com moléculas orgânicas e formar o PAN (peroxiacetilnitrato) composto altamente tóxico que estabiliza e transporta o nitrogênio reativo para zonas rurais, onde a reação em equilíbrio recompõe o $\mathrm{NO}_{2}$. Este, em presença de luz, pode gerar ozônio em regiões rurais. ${ }^{34}$ Posteriormente, radicais $\mathrm{OH}$ reagem com o $\mathrm{NO}_{2}$ gerando ácido nítrico $\left(\mathrm{HNO}_{3}\right)$, que pode retornar ao solo por processo de deposição seca ou úmida e vir a reagir com espécies básicas inertes presentes no solo, como $\mathrm{Al}_{2} \mathrm{O}_{3}$ ou $\mathrm{PbO}$ liberando espécies tóxicas aos vegetais $\left(\mathrm{Al}^{3+}\right)$ ou ao homem $\left(\mathrm{Pb}^{2+}\right)$. O nitrato, produto destas reações, pode ser lixiviado para águas de um rio e favorecer a eutrofização dessas; a ação de bactérias naturais pode transformar o nitrato em óxido nitroso $\left(\mathrm{N}_{2} \mathrm{O}\right)$ que retorna a atmosfera como um gás inerte na troposfera, mas com propriedades de gás estufa afetando o balanço energético da atmosfera e provocando o aumento da sua temperatura. ${ }^{35}$ Posteriormente o gás $\mathrm{N}_{2} \mathrm{O}$ já na estratosfera pode atuar como catalisador e decompor as moléculas de ozônio diminuindo a concentração da camada protetora do ozônio na estratosfera. Tudo isto provocado por um único átomo de nitrogênio que sofre transformações químicas e transita entre vários compartimentos ambientais.

\section{CICLO DO FÓSFORO}

A demanda por compostos de fósforo está crescendo e acompanhando a demanda da agricultura intensiva. Cerca de $96 \%$ do total da produção de fósforo $\left(19,8 \mathrm{Tg}\right.$ ano $\left.^{-1}\right)$ é direcionado à produção de produtos agrícolas. Os $4 \%$ restantes são utilizados na produção de diferentes produtos, como pesticidas, produtos farmacêuticos, retardantes de chama, vidros, plásticos e papéis. ${ }^{14} \mathrm{~A}$ indústria da produção de fósforo utiliza rochas como matéria prima. O fósforo natural que entra no ambiente é resultado do intemperismo sobre estas rochas (15-20 $\mathrm{Tg}$ ano $\left.^{-1}\right)$ e é similar em quantidade à produção industrial. Antes da revolução industrial, a entrada de fósforo natural no ambiente era compensada pela sedimentação natural do elemento no fundo do oceano. Porém, com o acréscimo da entrada do fósforo produzido pelo homem no ambiente, a tendência é uma acumulo do fósforo no ambiente. Um estudo em 25 países da Europa mostrou que o acúmulo de $\mathrm{P}$ variou entre $0,7-57,2 \mathrm{~kg} \mathrm{P} \mathrm{ha}^{-1}$ ano $^{-1}$ e que o acúmulo ocorreu em todos os países estudados. ${ }^{14}$

O fósforo $($ nox +5$)$ presente no fertilizante na forma de fosfato é mais estável sob o ponto de vista de reações de oxirredução, porém reage formando compostos pouco solúveis com quase todos os cátions presentes no solo. Em solos ácidos, como os que ocorrem naturalmente no Brasil, a presença de ferro e alumínio favorece a formação dos compostos poucos solúveis $\mathrm{AlPO}_{4} \cdot 2 \mathrm{H}_{2} \mathrm{O}$ (variscita) e $\mathrm{FePO}_{4} \cdot 2 \mathrm{H}_{2} \mathrm{O}$ (estrengita). ${ }^{36}$ No ambiente não apenas águas superficiais arrastam o fosfato presente no solo para rios e lagos, mas a erosão também o faz quando parte do solo contendo fosfato é transportado para um corpo de água. $\mathrm{O}$ fósforo, junto com o nitrogênio reativo, é promotor de eutrofização de águas, e como é geralmente o elemento limitante sua disponibilidade desencadeia o processo. ${ }^{37}$ A eutrofização de águas é um problema que afeta não só a disponibilidade de água potável como também limita as possibilidades de uso do corpo de água. Em alguns casos não é possível sequer o uso para recreação. ${ }^{38}$

\section{MUDANÇA CLIMÁTICA}

Os estudos apresentados no Painel Intergovernamental sobre Mudanças Climáticas ${ }^{39}$ IPCC concluíram que é importante buscar uma faixa de concentração atmosférica limite para os gases que atuam sobre o balanço energético da atmosfera. Como os gases que atuam para modificar o efeito estufa são provenientes de emissão direta, só é possível controlar a concentração destes gases na atmosfera limitando sua emissão. Além da dificuldade política, existem dificuldades práticas nesta limitação. É necessário aumentar o uso de energia não só para novos carros de passeio, mas para prover distribuição de água potável e iluminação elétrica em países pobres. Estudos também sugerem que outros fatores ambientais naturais induzidos por mudanças ambientais em curso podem também aumentar emissões de gases estufa. Apesar da evidente interação entre os ciclos do nitrogênio e do carbono, pouca atenção tem sido dada à promoção de estudos mostrando o quanto um pode atuar sobre o outro. A disponibilidade de nitrogênio reativo na superfície dos mares pode ser um fator que indiretamente contribui para emissão de gases estufa. Mares próximos aos grandes centros ou foz de rios comprometidos 
com excesso de compostos de nitrogênio podem sofrer inicialmente com um crescimento excessivo de algas, e com isto retirar $\mathrm{CO}_{2}$ da atmosfera. Ao final do ciclo de vida destas espécies, a morte em massa destas algas pode resultar em zonas anóxicas devido ao excesso de matéria orgânica morta cuja decomposição consome o oxigênio dissolvido na água. Com a ausência de oxigênio o processo que se segue é a reemissão de carbono para atmosfera na forma de metano, molécula com cerca de 24 vezes a capacidade de atuar como gás estufa comparada com o $\mathrm{CO}_{2}$. A adição de fertilizante nitrogenado na forma de amônio ao cultivo de arroz em áreas alagadas estimula o crescimento das bactérias geradoras de metano presentes na sua raiz e aumenta a emissão de gás metano. ${ }^{40}$

A construção das usinas hidrelétricas de Belo Monte e Babaquara na região amazônica prevê inundação de área de 6580 milhões de $\mathrm{m}^{2}$ para formação de reservatório, o equivalente a 1,5 milhão de campos de futebol. As áreas anóxicas nas regiões profundas do reservatório podem favorecer a formação e emissão de gases do efeito estufa como $\mathrm{CO}_{2}, \mathrm{CH}_{4}$ e $\mathrm{N}_{2} \mathrm{O} .^{41}$ Estimativas de emissão de $\mathrm{N}_{2} \mathrm{O}$ por estas áreas inundadas deve ser três vezes maior que o emitido em florestas, ${ }^{42} \mathrm{O}$ que resulta em contribuição não só para o efeito estufa como para a potencial destruição do ozônio estratosférico.

$\mathrm{O}$ excesso de nitrogênio reativo no ambiente acelera processos biogênicos envolvidos na desnitrificação e nitrificação. Neste processo gases como $\mathrm{NO}$ e $\mathrm{N}_{2} \mathrm{O}$ são emitidos para atmosfera. O gás $\mathrm{N}_{2} \mathrm{O}$, óxido nitroso, é conhecido pela sua alta eficiência de atuar como gás estufa, sua molécula equivale a cerca de 270 moléculas de dióxido de carbono no papel de gás estufa. Estudos sobre a emissão de óxido nitroso em áreas produtoras de cana de açúcar buscam conhecer sua taxa de emissão e sugerem que algumas práticas agrícolas podem estar comprometendo o papel do álcool combustível na sua única e vendável característica de não comprometer o ambiente, isto é, de possuir balanço zero na emissão de gases estufas quando considerado todo o ciclo de produção e uso deste combustível. ${ }^{33}$

A interdependência entre os ciclos do nitrogênio e carbono precisa ser mais bem conhecida para que não ocorram catástrofes naturais no futuro e que possam vir a mudar o clima de forma abrupta e não esperada.

\section{TAXA DE PERDA BIODIVERSIDADE}

Compostos de nitrogênio são transportados pela atmosfera como gás ou aerossol e sua dispersão no ambiente pode ocorrer mesmo em áreas naturais distantes das fontes de emissão, como reservas florestais e áreas remotas que de outra forma seriam intocadas pelo homem. Por exemplo, o transporte de nitrogênio pelo composto PAN até zonais florestais remotas pode liberar $\mathrm{NO}_{2}$ e induzir formação de ozônio em concentrações similares aos centros urbanos. ${ }^{43}$ Este fenômeno é maléfico aos organismos vegetais devido à característica fitotóxica deste gás oxidante. ${ }^{44}$

A deposição atmosférica de compostos de nitrogênio também pode ser significativa. Estudos sugerem que algumas florestas próximas de grandes centros receberam grande carga de compostos de nitrogênio a ponto de serem classificadas como saturadas neste elemento nutriente. Este estresse pode atuar na redução da floresta e talvez até no seu declínio. ${ }^{30,45}$ Isto porque a biodiversidade depende de um equilíbrio entre espécies que coexistem no ambiente da floresta. $\mathrm{O}$ excesso de nitrogênio pode favorecer algumas espécies vegetais que crescem com maior vigor e em detrimento a outras. Em condições extremas o excesso de nitrogênio pode levar a extinção de espécies menos afeitas ao elemento. Outro vilão é o ácido nítrico que pode depositar sobre a floresta e afetar o crescimento de vegetais susceptíveis às condições mais ácidas do ambiente, ou mesmo sua deposição no solo ou sedimento pode liberar espécies fitotóxicas que estavam imobilizadas na forma de óxidos básicos. Óxidos de nitrogênio catalisam a formação de ozônio troposférico, composto com características fitotóxicas, que segundo alguns estudos é responsável pelo declínio de florestas. ${ }^{46-49} \mathrm{O}$ excesso de nitrogênio reativo quando alcança águas superficiais pode induzir a eutrofização, processo que tem como uma das características a perda da biodiversidade. ${ }^{36}$

\section{USO DA TERRA}

Para minimizar a expansão do uso da terra é necessário focalizar atenções sobre a distribuição global das lavouras. As terras utilizadas na agricultura intensiva deveriam ser acompanhadas por monitoramento e exigência de boas práticas agrícolas evitando excessos no uso de fertilizantes e agrotóxicos. Medidas para conter a erosão que inviabiliza o uso da terra para agricultura são fundamentais. É preciso reconhecer que a agricultura intensiva pode ser tão ou mais prejudicial ao ambiente quanto indústrias poluidoras. A legislação e o controle de atividades industriais são regulados e fiscalizados pelo poder público e de forma similar deveriam ser expandidas para a agricultura. A prática agrícola livre do controle do passivo ambiental ajuda a mover a fronteira agrícola. Nações muito pobres, onde a lavoura é levada a exaustão pela saída de nutriente maior que a capacidade de reposição, deveriam ser de algum modo atendidas para evitar o problema. A expansão da fronteira agrícola se dá nestes países, pela busca de novas terras mais férteis. A produção de proteína animal não deveria ser incentivada, já que quando o animal se alimenta de ração é necessário grande consumo de nitrogênio em grandes áreas de cultivo de grãos usados na produção de ração. Já o gado que se alimenta de pastagens requer áreas extensas para produção destas pastagens. A produtividade do solo pode também ser afetada pela precipitação ácida e o ácido nítrico pode ser um vilão, já que ele é um ácido forte.

A produção e o uso de grandes quantidades de fertilizantes nitrogenados foram, até o momento, pouco questionados até pela ciência. É difícil questionar o uso de fertilizantes para produzir alimentos, mas fica mais fácil questionar o papel da agricultura para a produção de combustível. O custo do passivo ambiental local gerado pelo acúmulo de nitrogênio precisa ser contabilizado. É possível fazer isto sem realmente avançar sobre áreas com potencial agrícola? O clima da Amazônia não viabiliza a produção de cana de açúcar, argumento utilizado pelos defensores do álcool combustível. Mas a substituição da lavoura de produção de alimentos por cana em regiões tradicionalmente produtoras de alimento não empurra a produção de alimentos para novas áreas agrícolas?

\section{ACIDIFICAÇÃO OCEÂNICA}

Os oceanos estão ficando mais ácidos devido ao aumento da concentração de dióxido de carbono na atmosfera. O gás de características ácidas absorvido pela superfície do oceano aumenta a disponibilidade do íon $\mathrm{H}^{+}$. O aumento da emissão de $\mathrm{NO}$ e $\mathrm{SO}_{2}$ por processos de combustão aumenta a concentração de ácido nítrico e ácido sulfúrico na atmosfera, que por sua vez por processo de deposição pode aumentar o problema da acidez dos oceanos. A utilização de combustível com baixo teor de enxofre é uma tendência mundial. Diferentes processos estão sendo implementados para redução do enxofre no combustível. No Brasil, a implementação do diesel S-50 (50 ppm de enxofre no combustível) é resultado da resolução $\mathrm{n}^{\circ} 32$ da Agência Nacional do Petróleo, Gás Natural e Biocombustíveis (ANP).$^{50}$ Com isto emissões de $\mathrm{SO}_{2}$ e posterior formação do $\mathrm{H}_{2} \mathrm{SO}_{4}$ atmosférico devem ser diminuídas local e globalmente. Como resultado, as grandes cidades próximas ao litoral devem afetar menos áreas oceânicas com relação à deposição de ácido sulfúrico. Com relação à deposição de ácido nítrico proveniente de combustão, o problema 
é mais complexo, já que ele é produto da combustão feita com o uso de ar atmosférico. Separar o nitrogênio $\left(\mathrm{N}_{2}\right)$ do oxigênio $\left(\mathrm{O}_{2}\right)$ antes das reações de combustões não é viável. Catalisadores usados em canos de escapamento de veículos e em termoelétricas ainda são pouco eficientes para minimizar de forma eficiente a emissão de NO. O maior uso de termoelétricas mesmo no Brasil contribui para a emissão de NO. Com isto as grandes cidades próximas do litoral que utilizam meios de transporte movidos por motor à combustão e geram energia por queima de combustível devem intensificar o aumento da acidez da águas litorâneas. O alerta sobre a deposição dos compostos ácidos de nitrogênio não é recente e foi discutido no artigo "Is coastal eutrophication out of control?" de J. Pelley. ${ }^{51}$ Mas não são apenas os compostos de nitrogênio que agravam o problema da acidez de águas oceânicas. $\mathrm{O}$ excesso de nutriente como nitrato ou íon amônio favorece o crescimento do fitoplâncton e, após o seu ciclo de vida, a matéria orgânica morta resultante sofre decomposição e gera $\mathrm{CO}_{2}$ que favorece a acidificação da água.

\section{UTILIZAÇÃO DE ÁGUA DOCE}

Águas superficiais interiores são impactadas por compostos de nitrogênio provenientes de deposição atmosférica, escoamento de águas superficiais provenientes de lavouras, esgoto in natura de cidades e águas provenientes de ETE. A carga de compostos de nitrogênio destas águas é grande. Mesmo águas subterrâneas recebem carga alta de nitrato. Estudos mostram que a contaminação das águas subterrâneas com nitrato é uma preocupação global. ${ }^{52-56} \mathrm{O}$ nitrato em excesso presente nas águas utilizadas para abastecimento público podem trazer graves problemas a saúde de crianças. ${ }^{57,58}$ Por outro lado, o número de represas no Estado de São Paulo que estão eutrofizadas é facilmente constatável por simples observação. O excesso de nutrientes favorece o aparecimento de algas que podem alterar o odor ou gosto da água e podem produzir toxinas que inviabilizam o uso destas águas para o abastecimento humano ou de animais. ${ }^{45,59,60}$ O aumento da emissão de compostos nitrogenados para atmosfera e especialmente a amônia favorece a formação de aerossóis iônicos e higroscópicos. Em áreas continentais estes aerossóis são responsáveis pela nucleação de nuvens e também pela formação de chuva. O ciclo hidrológico está, desta forma, diretamente ligado ao ciclo do nitrogênio. Mudanças no ciclo hidrológico de algumas regiões aparentemente estão sendo controladas por emissões de gases e aerossóis iônicos contendo espécies como o nitrato e amônio. ${ }^{61}$

\section{DEGRADAÇÃO DO OZÔNIO ESTRATOSFÉRICO}

O Protocolo de Montreal, nos termos da Convenção de Viena para a Proteção da Camada de Ozônio, reduziu em 95\% a utilização de clorofluorcarbonos (CFCs) e os halogênicos. A partir de $1^{\circ}$ de janeiro de 2010 sua produção foi suspensa nas 195 nações signatárias do protocolo. Espera-se que, para o futuro, a degradação do ozônio estratosférico seja revertida. No entanto, o gás $\mathrm{N}_{2} \mathrm{O}$ pode se tornar o principal gás emitido por atividades humanas no século XXI e com propriedade para atuar sobre o ozônio, pois na estratosfera o óxido nitroso sofre decomposição fotoquímica, produzindo NO, que por sua vez reage com ozônio, como indicam as equações 7 a $10 .^{62,63}$

$$
\begin{gathered}
\mathrm{N}_{2} \mathrm{O}+h v \rightarrow \mathrm{N}_{2}+\mathrm{O} \\
\mathrm{N}_{2} \mathrm{O}+\mathrm{O} \times \rightarrow 2 \mathrm{NO} \\
\mathrm{O}_{3}+\mathrm{NO} \rightarrow \mathrm{NO}_{2}+\mathrm{O}_{2} \\
\mathrm{O}+\mathrm{NO}_{2} \rightarrow \mathrm{NO}+\mathrm{O}_{2}
\end{gathered}
$$

A soma das reações 9 e 10 mostram que o consumo do ozônio é catalisado pelos óxidos de nitrogênio (equação 11).

$$
\mathrm{O}_{3}+\mathrm{O} \rightarrow 2 \mathrm{O}_{2}
$$

A concentração do $\mathrm{N}_{2} \mathrm{O}$ passou de 270 a 319 ppb de 1900 a 2005, com acréscimo linear de 0,8 ppb ano ${ }^{-1}$ nas últimas décadas. ${ }^{64}$ O gás não faz parte do Protocolo de Montreal e a expectativa é que sua emissão aumente de $35-60 \%$ até $2030 .{ }^{65}$ As principais fontes de emissão de $\mathrm{N}_{2} \mathrm{O}$ são os processos de nitrificação e desnitrificação típicos de ambientes aquáticos. Estes processos se intensificam em ambientes com excesso de nitrogênio decorrente da agricultura e em áreas alagadas como grandes reservatórios de usinas hidrelétricas. Neste último caso, este efeito ambiental é raramente considerado no planejamento e adoção desta matriz energética. ${ }^{66}$

\section{EMISSÃO DE AEROSSÓIS}

Os aerossóis de maior tempo de residência na atmosfera e que podem atuar muito distante de suas fontes são as partículas mais finas e que são formadas na atmosfera. Um mecanismo importante de formação de aerossóis na atmosfera é a reação entre ácido e amônia presente na atmosfera. Os gases ácidos englobam uma série de compostos químicos formados a partir principalmente dos óxidos de nitrogênio ou enxofre. Porém, o único gás básico presente na atmosfera e em concentração significativa é o gás amônia. ${ }^{67}$ Todos os aerossóis de caráter iônico formados na atmosfera apresentam na sua composição o íon amônio. Estes são importantes porque interferem no balanço radiativo refletindo a radiação proveniente do sol e diminuindo a temperatura da atmosfera. Estes nucleadores de partículas iônicas formam partículas finas que podem ser inaladas pelos seres vivos e atingir partes mais profundas do trato respiratório e causar danos à saúde humana. A característica higroscópica destas partículas possibilita que estas absorvam umidade do ar e atuem como nucleadores de nuvens e podem assim afetar o ciclo hidrológico de uma região. ${ }^{68,69}$

\section{CONCLUSÕES}

As mudanças globais que estão em andamento são preocupantes porque podem afetar o planeta como um todo. Os eventos que podem ser creditados ao fenômeno acabam tendo repercussão na mídia mundial. A discussão e o entendimento sobre o tema são amplos por parte da sociedade civil. Emissões de dióxido de carbono, pegada do carbono, atividades com emissão zero de carbono e sustentabilidade são palavras comuns utilizadas em várias atividades e todas relacionadas ao ciclo do carbono. Porém, isto contrasta com a falta de conhecimento da sociedade sobre os compostos de nitrogênio e seus efeitos no ambiente. Possivelmente porque a ação e efeitos adversos dos compostos de nitrogênio no ambiente são locais ou regionais e dependem de ações locais para controle de uso e emissão para o ambiente. Ou talvez porque seus efeitos no ambiente, como o processo de eutrofização de uma represa, mostre pouco apelo jornalístico. Mas o fato é que o acumulo de nitrogênio antrópico no ambiente já ultrapassou processos naturais e continua crescendo quase sem limitações, desprezado pelo poder público e longe do conhecimento público, que poderia vir a gerar ações de pressão e controle. A química do nitrogênio no ambiente provoca o efeito cascata e este é um apelo interessante sob o ponto de vista ambiental. Não menos fascinante sob o aspecto químico são as reações de transformação das espécies químicas de nitrogênio no ambiente e que produzem compostos com papéis completamente opostos atuando no ambiente. $\mathrm{O}$ gás $\mathrm{NO}_{2}$ na troposfera é catalisador da formação do ozônio e o gás $\mathrm{N}_{2} \mathrm{O}$ na estratosfera catalisa o consumo de ozônio. $\mathrm{O}$ $\mathrm{NO}_{2}$ na troposfera pode gerar nitrato, um promotor do crescimento vegetal, ou promover a formação de ozônio, gás fitotóxico. A acidez 
da atmosfera pode aumentar pela presença de ácido nítrico $\left(\mathrm{HNO}_{3}\right)$ ou pode ser neutralizada pela amônia $\left(\mathrm{NH}_{3}\right)$, gás de propriedades básicas. Aos químicos urge a necessidade de se colocar o nitrogênio no foco das discussões em sala de aula, nos eventos científicos, nos temas de pesquisa. A sociedade precisa discutir projetos de desenvolvimento não apenas sob o aspecto do carbono, mas também do nitrogênio porque as maiores consequências ambientais do excesso de nitrogênio são principalmente locais e regionais. Minimizar o problema dependerá de uma posição da sociedade para estabelecer leis e mecanismos de controle estaduais ou nacionais. Cabe à ciência catalisar esta discussão.

\section{AGRADECIMENTOS}

Os autores G. Garcia e O. A. M. Santos agradecem ao CNPq e CAPES pelas bolsas de doutorado e A. A. Cardoso à FAPESP e CNPq pelo auxilio financeiro a projetos desenvolvidos sobre o tema no grupo de pesquisa.

\section{REFERÊNCIAS}

1. Stern, F. R.; Einstein's German World, Princeton University Press: New Jersey, 1999.

2. Rockström, J.; Steffen, W.; Noone, K.; Persson. A.; Chapin, S.; Lambin, E. F.; Lenton, T. M.; Scheffer, M.; Folke, C.; Schellnhuber, H. J.; Nykvist, B.; de Wit, C. A.; Hughes, T.; Leeuw, S. V. D.; Rodhe, H.; Sörlin, S.; Snyder, P. K.; Costanza, R.; Svedin, U.; Falkenmark, M.; Karlberg, L.; Corell, R. W.; Fabry, V. J.; Hansen, J.; Walker, B.; Liverman, D.; Richardson, K.; Crutzen, P.; Foley, J. A.; Nature 2009, 461, 472.

3. Galloway, J. N.; Aber, J. D.; Erisman, J. W.; Seitzinger, S. P.; Rowarth, R. W.; Cowling, E. B.; Cosby, B. J.; BioScience 2003, 53, 341.

4. Mackenzie, F. T.; Our Changing Planet: An Introduction to Earth System Science and Global Environmental Change, $4^{\text {th }}$ ed., Prentice Hall: Londres, 2010

5. Ohlweiler, O. A.; em Química Inorgânica; Blücher, E. ed.; EDUSP: São Paulo, 1971.

6. Leigh, G. J.; The World's Greatest Fix: A History of Nitrogen and Agriculture, $1^{\text {st }}$ ed., Oxford University Press: New York, 2004.

7. Levine, J. S.; Augustsson, T. R.; Andersont, I. C.; Hoell, J. M.; Atmos. Environ. 1984, 18, 1797.

8. Pereira, E. A.; Machado, C. M. D; Cardoso, A. A.; QNEsc 2008, $28,9$.

9. Galloway, J. N.; Schlesinger, W. H.; Levy, H.; Michaels, A.; Schnoor, J. L.; Global Biogeochem. Cycles 1995, 9, 235.

10. Vitousek, P. M.; Naylor, R.; Crews, T.; David, M. B.; Drinkwater, L. E.; Holland, E.; Johnes, P. J.; Katzenberger, J.; Martinelli, L. A.; Matson, P. A.; Nziguheba, G.; Ojima, D.; Palm. C. A.; Robertson, G. P.; Sanchez, P. A.; Townsend, A. R.; Zhang, F. S.; Science 2009, 234, 1510.

11. Frejka, T.; IESBS 2001, 6244.

12. Smil, V.; Sci. Am. 1997, 277, 76.

13. Keeney, D. R.; Hatfield, J. L. em Nitrogen in the environment: sources, problems and management; Keeney, D. R.; Hatfield, J. L, eds; Elsevier: Amsterdan, 2008, cap. 1.

14. Liebig, J. V.; Die organische Chemie in ihrer Anwendung auf Agrikultur und Physiologie, Vieweg: Braunschweig, 1841.

15. Standage, T.; A história comestível da humanidade, $1^{\text {st }}$ ed., Jorge Zahar: Rio de Janeiro, 2010.

16. http://www.onu.org.br/a-onu-em-acao/a-onu-em-acao/a-onu-e-a-populacao-mundial, acessada em Dezembro 2012.

17. Penrose Jr, R. A. F.; J. Geol. 1910, 18, 1.

18. Dawson, C. J.; Hilton, J.; Food Policy 2011, 36, 14

19. Chagas, A. P.; Quim. Nova 2007, 30, 240

20. Galloway, J. N.; Environ. Pollut. 1998, 102, 15.
21. http://minerals.usgs.gov/minerals/pubs/commodity/nitrogen/mcs-2012nitro.pdf, acessada em Dezembro 2012.

22. http://www.fertilizer.org/ifa/statistics/indicators/ind_reserves, acessada em Dezembro 2012.

23. Fixen, P. E.; West, F. B. AMBIO 2002, 31, 169

24. Leach, A. M.; Galloway, J. N.; Bleeker, A.; Erisman, J. W.; Kohn, R.; Kitzes, J.; Environmental Development 2012, 1, 40.

25. Martinelli, L. A.; Os caminhos do nitrogênio - do fertilizante ao poluente; Informações Agronômicas, 2007, $\mathrm{n}^{\circ}$ 118, p. 6-10. Disponível em http://www.ipni.net/publication/ia-brasil.nsf/0/1CA52B5C86392D 5D83257AA10060F4B3/\$FILE/Page6-10-118.pdf, acessada em Julho 2013.

26. Galloway, J. N.; Townsen, A. R.; Erisman, J. W.; Bekunda, M.; Cai, Z.; Freney, J. R.; Martinelli, A. L.; Seitzinger, S. P.; Sutton, M. A.; Science 2008, 320, 889 .

27. Benn, F. R.; Mcauliffe, C. A; Química e Poluição, LTC: São Paulo, 1981.

28. http://www.saae.sp.gov.br/arquivos/snis_2003_1.pdf, acessada em Dezembro 2012.

29. Allen, A. G; Cardoso, A. A.; Wiatr, A.; Machado, C. M. D.; Paterlini, W. C.; Baker, J.; J. Braz. Chem. Soc. 2010, 21, 87.

30. Allen, A. G.; Machado, C. M. D.; Cardoso, A. A.; Environ. Pollut. 2011, 159, 1190

31. Payne, R.; Dise, N. B.; Stevens, C. J.; Gowing, D. J.; Partners, G.; PNAS 2012, 110, 984.

32. Machado, C. M. D.; Cardoso, A. A.; Allen, A. G.; J. Environ. Sci. Technol. 2008, 42, 381.

33. Crutzen, P. J.; Mosier, A. R.; Smith, K. A.; Winiwarter, W.; Atmos. Chem. Phys. 2008, 8, 389.

34. Garcia, G.; Allen, A. G.; Cardoso, A. A.; J. Environ. Monit. 2010, 12, 1325 .

35. Carmo, J. B.; Filoso, S.; Zotelli, L. C.; Sousa Neto, E. R.; Pitombo, L. M.; Duarte-Neto, P. J.; Vargas, V. P.; Andrade, C. A.; Gava, G. J. C.; Rossetto, R.; Cantarella, H.; Neto, A. E.; Martinelli, L. A.; GCB Bioenergy 2013, 5, 267.

36. Pierzynski, G. M.; Sims, J. T.; Vance, G. F.; Soils and Environmental Quality, $3^{\text {rd }}$ ed., CRC Press: Boca Raton, 2005.

37. Conley, D. J.; Paerl, H. W.; Howarth, R. W.; Boesch, D. F.; Seitzinger, S. P.; Havens, K. E.; Lancelot, C.; Likens, G. E.; Science 2009, 323, 1014.

38. Wang, Q. S.; Sun, D.; Hao, W.; Li, Y.; Mei, X.; Acta Ecol. Sin. 2012, 32, 174.

39. http://www.ipcc.ch/index.htm\#.UL03g-TWIdV, acessada em Dezembro 2012.

40. Bodelier, P. L. E.; Roslev, P. ; Henckel1, T. ; Frenzel1, P. ; Nature 1999, 403, 421.

41. Fearnside, P. M. Novos Cadernos NAEA. 2009, 12, 5.

42. http://philip.inpa.gov.br, acessada em Abril 2013.

43. Birks, J. W. em Perspectives in Environmental Chemistry; Macalady, L. D., ed.; Oxford University Press: New York, 1998.

44. Aikin, A. C.; Herman, J. R.; Maier, E. J. R.; Mcquillan, C. J.; Phef. Space Sci. 1983, 31, 1075.

45. Aber, J. D.; Nadelhoffer, K. J.; Steudler, P.; Melillo, J. M.; BioScience 1989, 39,378

46. Grulke, N. E.; Andersen, C. P.; Fenn, M. E.; Miller, P. R.; Environ. Pollut. 1998, 103, 63

47. Percy, K. E.; Legge, A. H.; Krupa, S. V.; Developments in Environmental Science 2003, 3, 85.

48. Kefauver, S. C.; Peñuelas, J.; Ustin, S.; Atmos. Environ. 2012, 62, 41.

49. Ollinger, S. V.; Aber, J. D.; Reich, P. B.; Ecol. Appl. 1997, 7, 1237.

50. http://nxt.anp.gov.br/NXT/gateway.dll/leg/resolucoes_anp/2007/outubro/ ranp\%2032\%20-\%202007.xml, acessada em Abril 2013.

51. Pelley, J.; Environ. Sci. Technol. 1999, 32, 462.

52. Cabral, N. M. T.; Quim. Nova 2007, 30, 1804. 
53. Chen, S.; Wu, W.; Hu, K.; Li, W.; Ecol. Complex. 2010, 7, 131.

54. Wick, K.; Heumesser, C.; Schmid, E.; J. Environ. Manage. 2012, 111, 178.

55. Sadurski, A.; em Nitrates in Groundwater; Jaworek, L. R.; Sadurski, A., eds.; Taylor and Francis CRC: Londres, 2005.

56. Showers, W. J.; Genna, B.; Mcdade, T.; Bolich, R.; Fountain, J. C.; Environ. Sci. Technol. 2008, 42, 4683.

57. Nascimento, T. S.; Pereira, R. O. L.; Mello, H. L. D.; Costa, J.; Rev. Bras. Anestesiol. 2008, 58, 65.

58. Van Grinsven, H. J. M. ; Rabl, A.; Kok, T. M.; Environmental Health $\mathbf{2 0 1 0}, 23,9$.

59. Schindler, D. W.; Hecky, R. E.; Science 2009, 324, 721.

60. http://www.who.int/water_sanitation_health/bathing/srwe1-chap8.pdf, acessada em Janeiro 2013.

61. Silva, L. C.; Souza, M. L.; Allen, A. G.; Cardoso, A. A.; Campos, M. L. A. M.; Nogueira, R. F. P.; J. Geophys. Res. 2003, 108, 4207.
62. Ravishankara, A. R.; Daniel, J. S.; Portmann, R. W.; Science 2009, 326, 123.

63. Manahan, E. S.; Environmental Chemistry, $6^{\text {th }}$ ed., CRC Press: Boca Raton, 1994.

64. http://www.ipcc.ch/publications_and_data/ar4/wg1/en/tssts-2-1-1.html, acessada em Dezembro 2012.

65. Aguilera, E.; Lassaletta, L.; Sanz-Cobena, A.; Garnie, J.; Vallejo, A.; Agric. Ecosyst. Environ. 2013, 164, 32.

66. Guimarães, G. P.; Mello, W. Z.; Quim. Nova 2008, 31, 7.

67. Félix, E. P.; Cardoso, A. A.; Quim. Nova 2004, 27, 123.

68. Spurny, K. R.; J. Aeros. Sci. 1996, 27, S473.

69. Mircea, M.; Facchini, M. C.; Decesari, S.; Cavalli, F.; Emblico, L.; Fuzzi, S.; Vestin, A.; Rissler, J.; Swietlicki, E.; Frank, G.; Andreae, M. O.; Maenhaut, W.; Rudich, Y.; Artaxo, P.; Atmos. Chem. Phys. 2005, 5, 3111 . 